\title{
Role of Transesophageal Echocardiography in Patient with Tetralogy of Fallot with Unilateral Absence of Pulmonary Artery undergoing Intracardiac Repair
}

\author{
${ }^{1}$ Shrinath Damodaran, ${ }^{2} \mathrm{KP}$ Gaurav, ${ }^{3}$ Shyam Thingnam, ${ }^{4}$ Vipan Garg, ${ }^{5}$ Sunder L Negi
}

\begin{abstract}
Unilateral absence of pulmonary artery (UAPA) is a rare congenital anomaly commonly associated with cardiovascular malformation. Tetralogy of Fallot (TOF) is the most frequent concomitant disorder for UAPA disease. Incidence of UAPA in TOF is 1 to $3 \%$. The absent left pulmonary artery (LPA) is 5 to 8 times more frequent than the right pulmonary artery (RPA). In this case report, emphasis has been given to the role of transesophageal echocardiography (TEE) in patients with UAPA with TOF undergoing intracardiac repair.
\end{abstract}

Keywords: Absent left pulmonary artery, Tetralogy of Fallot, Transesophageal echocardiography.

How to cite this article: Damodaran S, Gaurav KP, Thingnam S, Garg V, Negi SL. Role of Transesophageal Echocardiography in Patient with Tetralogy of Fallot with Unilateral Absence of Pulmonary Artery undergoing Intracardiac Repair. J Perioper Echocardiogr 2018;6(1):16-19.

Source of support: Nil

Conflict of interest: None

\section{CASE REPORT}

An 8-year-old female child, weighing $20 \mathrm{~kg}$, presented with bluish discoloration of skin since birth. On examination, the patient was hemodynamically stable (blood pressure 94/44 $\mathrm{mm} \mathrm{Hg}$, heart rate 80/minute) and maintaining room air oxygen saturation of $85 \%$. Baseline hemoglobin of patient was $16 \mathrm{gm} / \mathrm{dL}$ and other laboratory parameters were within normal limits. Transthoracic echocardiography (TTE) revealed large perimembranous ventricular septal defect (VSD) of $14 \mathrm{~mm}$ in size, severe infundibular stenosis with peak gradient of $90 \mathrm{~mm} \mathrm{Hg}$, $50 \%$ aortic override, right ventricular hypertrophy, and

${ }^{1,2}$ Cardiac Fellow, ${ }^{3}$ Professor, ${ }^{4}$ Junior Resident, ${ }^{5}$ Assistant Professor

1,2,4,5 Department of Anesthesia and Intensive Care, Postgraduate Institute of Medical Education and Research, Chandigarh, India

${ }^{3}$ Department of Cardiothoracic and Vascular Surgery, Postgraduate Institute of Medical Education and Research, Chandigarh, India

Corresponding Author: Sunder L Negi, Assistant Professor Department of Anesthesia and Intensive Care, Postgraduate Institute of Medical Education and Research, Chandigarh, India e-mail: dr.sundernegi@gmail.com absent LPA. Computed tomography (CT) pulmonary angiography showed main pulmonary artery and right pulmonary artery attenuated in caliber of 7.1 and $6.7 \mathrm{~mm}$ respectively, with LPA atresia. However, there was a large major aortopulmonary collateral artery of $3.9 \mathrm{~mm}$ supplying left lung. Computed tomography angiography (CTA) showed infundibular stenosis, VSD, and aortic override. Surgery was planned for total intracardiac repair.

The child was premedicated with $0.5 \mathrm{ug} / \mathrm{kg}$ of oral midazolam 1 hour before being shifted to operation room. Inside the operating room, electrocardiography, pulse oximetry, and noninvasive blood pressure were applied. Anesthesia was induced with inhalational sevoflurane; simultaneously, peripheral venous line was secured in right upper limb with $22 \mathrm{G}$ cannula followed by fentanyl $5 \mu \mathrm{g} / \mathrm{kg} /$ body weight and intubation was done with $5.5 \mathrm{~mm}$ cuffed endotracheal tube facilitated by vecuronium $0.1 \mathrm{mg} / \mathrm{kg}$. A 22-gauge arterial catheter was inserted in left radial artery and right internal jugular vein was cannulated with triple lumen catheter for central venous access. After induction of general anesthesia, a pediatric TEE probe (S7-3t, Philips iE33) was introduced. Anesthesia was maintained by isoflurane, fentanyl infusion $1 \mu \mathrm{g} / \mathrm{kg} / \mathrm{hour}$, and vecuronium boluses. A standard anticoagulation technique was used for all the patients before cannulation. Heparin $4 \mathrm{mg} /$ $\mathrm{kg}$ was given for achieving activated clotting time (ACT) more than 480 seconds. During bypass, ACT was obtained every hour, to determine the adequacy of anticoagulation.

\section{PREOPERATIVE TEE}

The TEE revealed large $14 \mathrm{~mm}$ perimembranous VSD (Fig. 1), severe right ventricular outflow tract (RVOT) obstruction with gradient of $59 \mathrm{~mm} \mathrm{Hg}$ (Fig. 2), 50\% aortic override (Fig. 3), single right pulmonary artery (Fig. 4), and left ventricle dimension of $34 \mathrm{~mL} / \mathrm{m}^{2}$ (Fig. 5).

Surgical procedure consisted of intracardiac repair with polytetrafluoroethylene patch closure of VSD, resection of RVOT obstruction and monocusp valve with transannular patch augmentation of RVOT under cardiopulmonary bypass (CPB) support. 


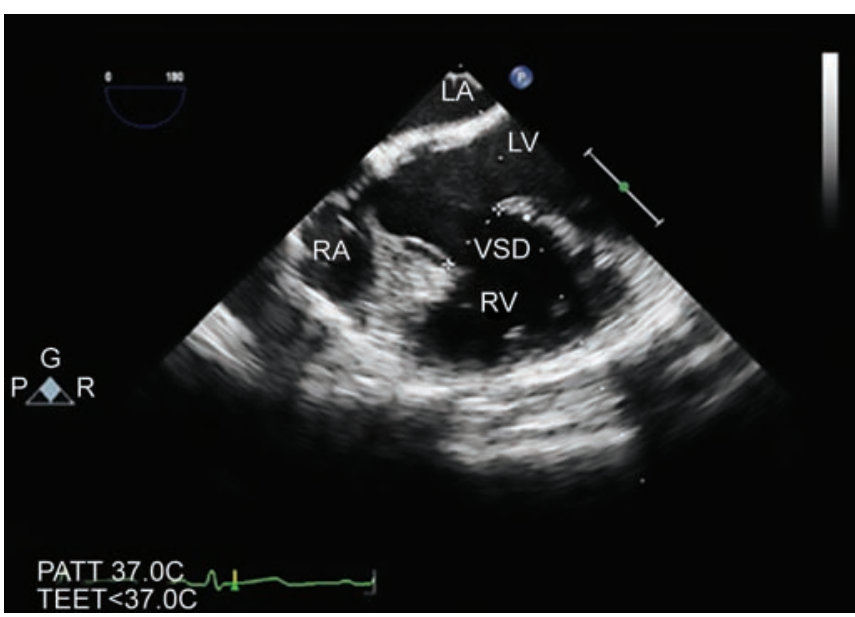

Fig. 1: Mid-esophageal 5-chamber view demonstrating a large ventricular septal defect (VSD) in tetralogy of Fallot

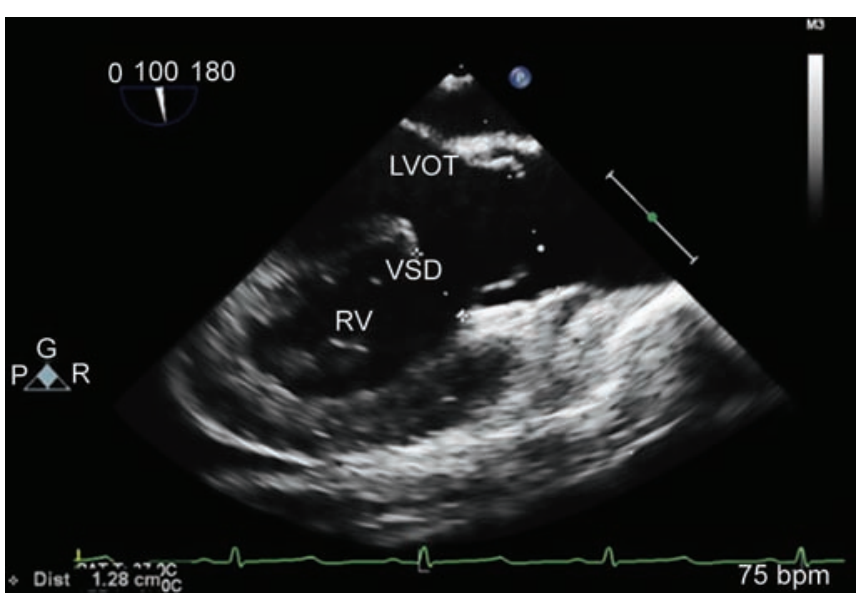

Fig. 3: Mid-esophageal long-axis view demonstrating the relationship of the large conoventricular ventricular septal defect (VSD) to the aorta (AO). Other structures seen in this view are the left ventricle outflow tract(LVOT) and right ventricle (RV)

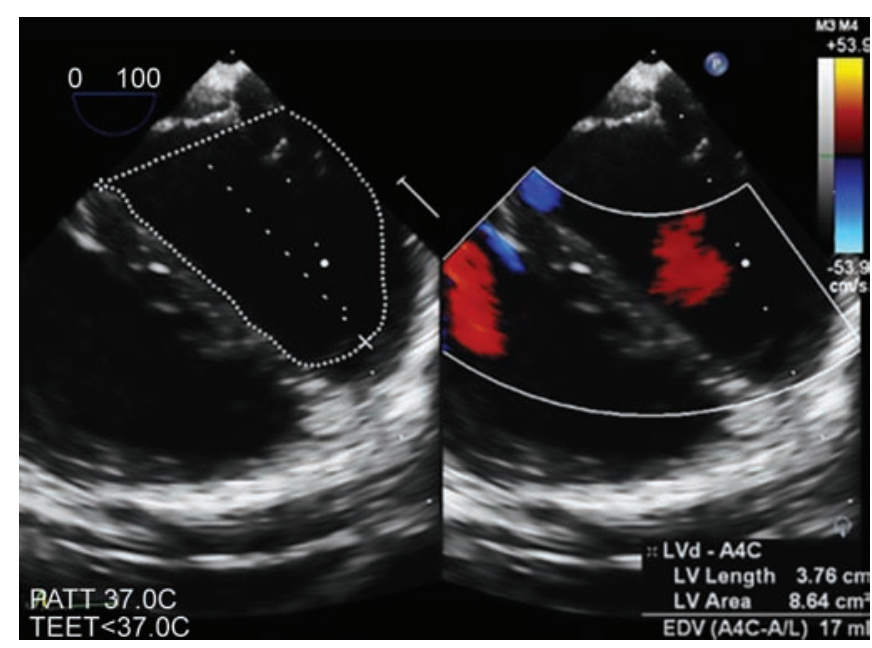

Fig. 5: Mid-esophageal 4-chamber view demonstrating left ventricular end diastolic volume

During rewarming, patient was loaded with milrinone $50 \mathrm{ug} / \mathrm{kg} /$ body weight. Patient was weaned off CPB on $0.30 \mu \mathrm{g} / \mathrm{kg} / \mathrm{min}$ milrinone and $0.1 \mu \mathrm{g} / \mathrm{kg} / \mathrm{min}$ noradrenaline infusion.

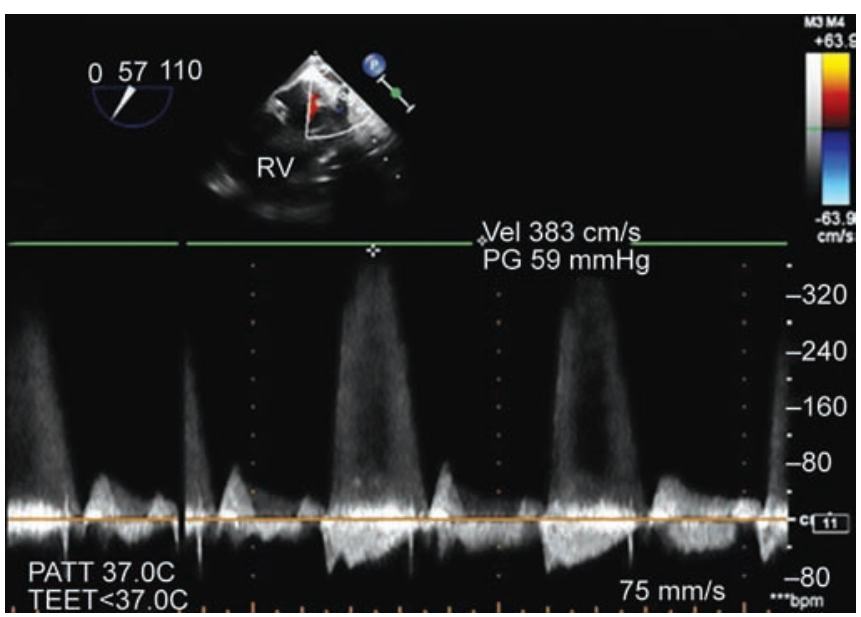

Fig. 2: Mid-esophageal right ventricle inflow outflow view displaying peak gradient across right ventricular outflow tract

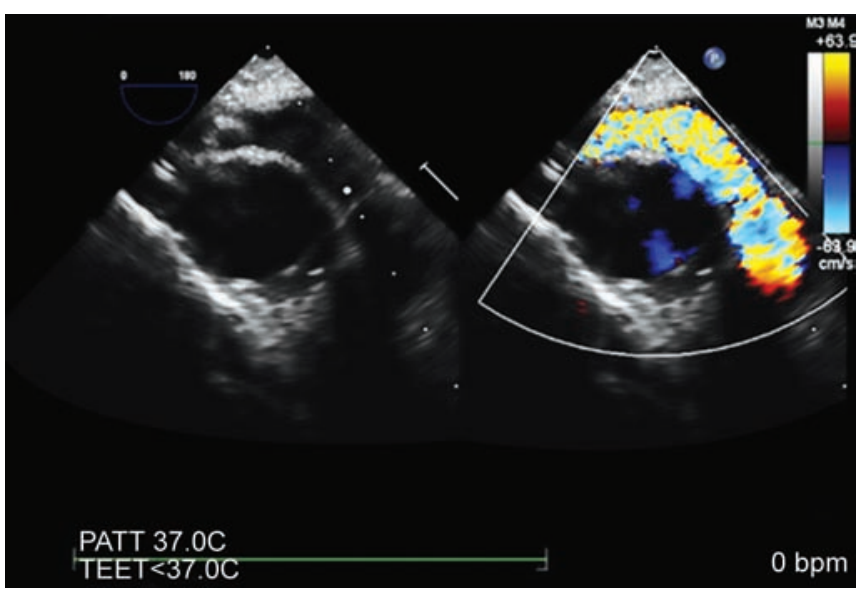

Fig. 4: Mid-esophageal ascending aortic short-axis view depicting the main pulmonary artery (MPA), right pulmonary artery (RPA) and color flow Doppler showing the turbulent flow in the main and right pulmonary artery

\section{POSTOPERATIVE TEE}

Post-CPB TEE revealed no residual shunt across the VSD patch (Fig. 6), peak gradient of $10 \mathrm{~mm} \mathrm{Hg}$ across the RVOT (Fig. 7), and no pulmonary regurgitation.

Patient was shifted to surgical intensive care unit. After 12 hours of elective ventilation, patient was extubated. Patient shifted to ward on postoperative day three and discharged from hospital on postoperative day 7 in good clinical condition.

\section{DISCUSSION}

Tetralogy of Fallot is the most common form of cyanotic congenital heart disease with a favorable outcome in most patients (less than $2 \%$ early mortality). ${ }^{1}$ Unilateral absence of pulmonary artery is a rare congenital anomaly that is commonly associated with cardiovascular malformation. The incidence of UAPA is $0.6 \% ; 40 \%$ of patients have the isolated form of lesion, whereas in $60 \%$ of cases, UAPA is combined with other congenital heart defects. ${ }^{2}$ Tetralogy 


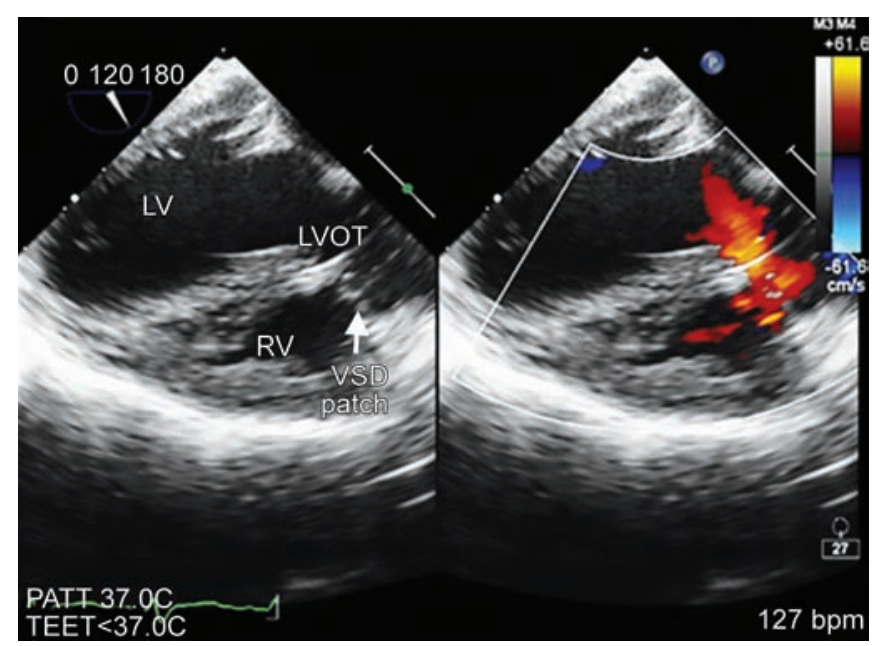

Fig. 6: Mid-esophageal long-axis view demonstrating ventricular septal patch, left ventricle and right ventricle

of Fallot is the most common concomitant disorder for UAPA. From 1 to $3 \%$ of patients with TOF have UAPA. ${ }^{3-5}$ Out of these, the absent LPA is 5 to 8 times more frequent than the right one. . $^{2,4}$

Intraoperative TEE is recommended for all patients undergoing intracardiac repair for TOF. ${ }^{6}$ Intraoperative TEE represents a complementary imaging modality for a TTE. During pre-bypass period, TEE overcomes the limitations of TTE, which include the poor window, especially in pediatric group of patients and confirms and/or excludes the preoperative findings. The pre-bypass TEE assessment should include evaluation of the VSD in terms of location, size, and margins. Doppler techniques should be applied to evaluate the nature, location, and severity of the RVOT obstruction. The size of the pulmonary annulus, valve morphology, and dimensions of the pulmonary arteries should be assessed. Left ventricular (LV) size and contralateral pulmonary artery size are two important factors which determine the outcome in patients with UAPA with TOF undergoing intracardiac repair. Zhang et al. ${ }^{5}$ found in their study that hospital mortality of patient with UAPA with TOF is 8.3 and $95 \% 15$-year survival. The authors also concluded that the main requirements for patients for a complete repair of TOF with concomitant UAPA are normal LV dimensions (end-diastolic volume greater than $30 \mathrm{~mL} / \mathrm{m}^{2}$ ) and normal size of the contralateral pulmonary artery (pulmonary arterial diameter to descending aorta diameter ratio greater than 1.5). In our case, we report that the $\mathrm{LV}$ dimension was $34 \mathrm{~mL} / \mathrm{m}^{2}$ and the size of contralateral pulmonary artery was $6.8 \mathrm{~mm}$.

Intraoperative TEE give us real-time information on volume status and cardiac function which helps in hemodynamic management and preventing hypercyanotic spells during pre-bypass period. During weaning from bypass, TEE allows for continuous monitoring of intracardiac air, ventricular function, and assessment of loading conditions. Post-bypass TEE helps in finding

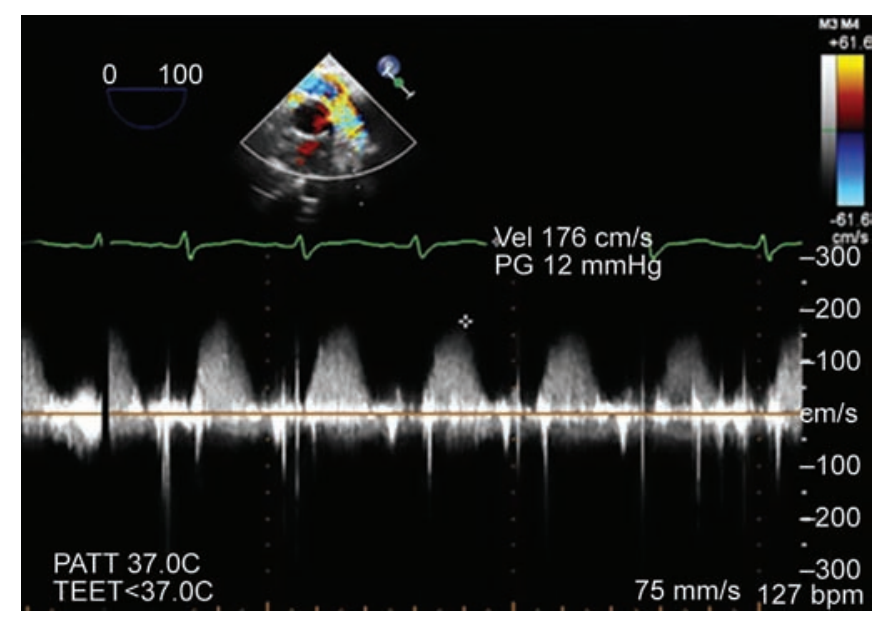

Fig. 7: Mid-esophageal ascending aortic short axis view showing peak gradient across RVOT after complete repair of TOF

out ventricular-level shunts across the patch. Thorough examination of the RVOT, pulmonary valve, and main and proximal branch pulmonary arteries should be done after coming off bypass. Papagiannis et $\mathrm{al}^{7}$ reported that postsurgical imaging led to a $13 \%$ incidence of immediate return to bypass to address either a residual VSD or significant RVOT obstruction. $\mathrm{Xu}$ et $\mathrm{al}^{8}$ found that intraoperative TEE led to immediate revision in $7 \%$ of patients. Intraoperative TEE also helps us to distinguish fixed from dynamic obstruction which further avoids unnecessary revisions. In our case report, we did not find any significant RVOT obstruction, residual shunt across the VSD patch, and pulmonary regurgitation.

The main goal of TEE is to detect problems prior to leaving the operating room to improve the outcome by permitting visualization of the operative procedure in real time and provides accurate guidance for the operating surgeon; it is also important to make out the need for determination of the risk to benefit ratio in return to bypass decisions.

In conclusion, the intraoperative TEE imaging is a safe and feasible diagnostic modality for the determination of LV size and contralateral pulmonary artery size in patients with UAPA with TOF during intracardiac repair. In the intraoperative period, TEE also facilitates detection of residual defects, guides the immediate surgical revision when necessary, and allows real-time hemodynamic monitoring. Intraoperative TEE accounts for improved clinical outcomes by decreasing morbidity and potentially reducing mortality.

\section{REFERENCES}

1. Nollert G, Fischlein T, Bouterwek S, Böhmer C, Dewald O, Kreuzer E, et al. Long-term results of total repair of tetralogy of Fallot in adulthood: 35 years follow-up in 104 patients corrected at the age of 18 or older. Thorac Cardiovasc Surg 1997 Aug;45(4):178-181. 
2. Kucera V, Fiser B, Tuma S, Hucin B. Unilateral absence of pulmonary artery: a report on 19 selected clinical cases. Thorac Cardiovasc Surg 1982 Jun;30(3):152-158.

3. Xia G. Tetralogy of Fallot with absence of the left pulmonary artery. Zhonghua Yi Xue Za Zhi 1990;70:128-130.

4. Liu JS, Wang ZW. Correction of tetralogy of Fallot in patients with a single pulmonary artery. Zhonghua Wai Ke Za Zhi 1994 Mar;32(3):172-174.

5. Zhang GC, Wang ZW, Zhang RF, Zhu HY, Yi DH. Surgical repair of patients with tetralogy of Fallot and unilateral absence of pulmonary artery. Ann Thorac Surg 1997 Oct;64(4):1150-1153.
6. Joyce JJ, Hwang EY, Wiles HB, Kline CH, Bradley SM, Crawford FA Jr. Reliability of intraoperative transesophageal echocardiography during tetralogy of Fallot repair. Echocardiography 2000 May;17(4):319-327.

7. Papagiannis J, Kanter RJ, Armstrong BE, Greeley WJ, Ungerleider RM. Intraoperative epicardial echocardiography during repair of tetralogy of Fallot. J Am Soc Echocardiogr 1993 Jul-Aug;6(4):366-373.

8. Xu J, Shiota T, Ge S, Gong Z, Rice MJ, Cobanoglu A, Sahn DJ. Intraoperative transesophageal echocardiography using high-resolution biplane $7.5 \mathrm{MHz}$ probes with continuouswave Doppler capability in infants and children with tetralogy of Fallot. Am J Cardiol 1996 Mar;77(7):539-542. 